\title{
Effect of boron, phosphorus and fluorine on shear stress relaxation in haplogranite melts
}

\author{
Nikolai Sh. BAGDASSAROV, Donald B. DINGWELL and SHARON L. WEBB
}

Bayerisches Geoinstitut, Universität Bayreuth, Postfach 1012 51, D-95440 Bayreuth, Germany

\begin{abstract}
Shear stress relaxation in haplogranite melts has been investigated using torsional deformation. Sinusoidal shear strains of small amplitude $\left(10^{-3}-10^{-5}\right)$ have been generated over 4 orders of magnitude of strain rate and a wide range of temperatures. The viscoelastic behavior of the investigated melts can be characterized in terms of the complex shear modulus, the complex shear viscosity, and the internal friction. With addition of $\mathrm{B}, \mathrm{P}, \mathrm{F}$ to a haplogranite melt, the relaxation spectrum becomes broader, skewing further towards shorter relaxation times. Thus, the solution of volatiles in highly polymerized melts leads to a broadening, in frequency-temperature space, of the viscoelastic region which separates liquid behavior from glassy behavior. The relaxation spectrum of pure haplogranite melt has an asymmetrical form which can be fitted by a stretched exponent with parameter $\beta \sim 0.5$. The boron-containing melts are characterized by $\beta \sim 0.4$, the phosphorus- and fluorine-containing melts yield $\beta<0.4$.

The unrelaxed shear modulus of the liquids obtained at high frequencies and low temperatures are in agreement with the results of new high-frequency $(20 \mathrm{MHz})$ ultrasonic measurements performed at room temperature. The additions of boron, phosphorus, and fluorine all result in decreases in the unrelaxed shear modulus.

The relaxed (or Newtonian) shear viscosity obtained from this study at low frequencies and high temperatures compares well with the data obtained by micropenetration viscometry on the same samples. The present low-temperature viscosity data together with high-temperature concentric cylinder viscometry measurements describe an Arrhenian relationship for all investigated compositions in the temperature range of $650-1650{ }^{\circ} \mathrm{C}$. The activation energy of viscous flow decreases with $\mathrm{B}, \mathrm{P}$ and $\mathrm{F}$ content.
\end{abstract}

Key-words: haplogranite melt, shear viscosity, complex shear modulus, shear stress relaxation spectrum, internal friction.

\section{Introduction}

The nature of viscous deformation in silicate melts has emerged, in recent years, as a central theme, linking the macroscopic transport properties of silicate melts to the microscopic structure of such materials (Sato \& Manghnani, 1985; Liu et al., 1988; Rivers \& Carmichael, 1987; Dingwell \& Webb, 1989, 1990; McMillan et al., 1992; Stebbins et al., 1992). Our current knowledge of the spectrum of relaxation processes in silicate melts is, however, incomplete. We know for example that the high-temperature relaxation mode responsible for viscous flow can be approximated in temperature-time space from the ratio of the relaxed loss modulus (Newtonian viscosity $\times$ strain rate) to the unrelaxed storage (elastic) modulus. Many aspects of transport in silicate melts, including Si self diffusivity (Dingwell \& Webb, 1990), nonbridging oxygen lifetimes (Liu et al., 1988; Farnan \& Stebbins, $1990 \mathrm{a}, \mathrm{b})$, backreaction of hydrous species during quenching (Silver, 1988 ) and the onset of non-Newtonian viscosity (Webb \& Dingwell, 1990) are usefully scaled by such an approximation. This modulus ratio and the corresponding mechanical model (the Maxwell model) remain nevertheless an approximation of the more detailed picture of relaxation processes provided by experimental methods in the frequency domain. 
Frequency-dependent determinations of relaxation (torsion, ultrasonics, dynamic loading) form a class of relaxation spectroscopy experiments where the isothermal frequency-dependent deformation of a melt can be studied under a wide range of strain rates $(\mathrm{mHz}-\mathrm{GHz})$ without the application of large strains (i.e. linear stress-strain behavior). The advantage of such techniques lies in their ability to transverse the relaxation peak due to structural mobility of $\mathrm{Si}$ and $\mathrm{O}$ and thus cross from the glassy to the liquid (or vice versa) regime of melt response. In generating such a relaxation spectrum one provides a constraint on the degree of complexity required to characterize the mechanisms of viscous deformation in silicate melts. These methods provide a complement to time domain studies of melt deformation, including most methods of viscometry and stress relaxation determinations which employ much larger strains.

Several components of silicate melts that are typically enriched in granitic magmas are known to have strong effects on the transport properties of silicate melts. Examples are fluorine, boron and phosphorus. The addition of these components, along with water, to a granitic base composition, represent, in a static topological sense, some of the most extreme changes in melt structure (degree of polymerization, $\mathrm{NBO} / \mathrm{T}$ ) that are to be expected in natural systems. How does the relaxation spectrum of a granitic melt change with the addition of such components? A shift of the entire relaxation peak to lower temperatures is one inevitable consequence of the accompanying viscosity reduction (Dingwell et al., 1993 a,b) but there are a number of further possibilities, including the broadening or tightening of the relaxation peak, a skewing of the peak toward higher or lower temperature, and the appearance of new, secondary peaks, in the relaxation spectrum near the glass transition. The present study addresses the above question by investigating the effects of $F$, $\mathrm{B}$ and $\mathrm{P}$ on the relaxation spectrum of haplogranitic melt. First we review some essential points of linear viscoelasticity.

\section{Linear viscoelastic relaxation}

The relaxation of a single internal variable $(\xi)$ as a function of time can be described by the firstorder kinetic equation

$$
\frac{\mathrm{d} \xi}{\mathrm{dt}}=-\frac{1}{\tau_{0}}(\xi-\bar{\xi})
$$

where $\bar{\xi}$ is the equilibrium value of $\xi$ and $\tau_{0}$ is the proportionality constant called the relaxation time (Nowick \& Berry, 1972). The solution of this equation is

$\xi=\bar{\xi}_{0}\left[1-\exp \left(-\mathrm{t} / \tau_{0}\right)\right]$.

This is Debye, or exponential, single-time relaxation behavior. If the internal variable $\xi$ oscillates with time as $\sim \mathrm{e}^{\mathrm{i} \omega t}$, then it depends on angular frequency $\omega$ and can be written as a complex function;

$\xi(\omega)=\xi^{\prime}(\omega)+i \xi^{\prime \prime}(\omega)$,

where $\xi$ ' is the Debye dynamic relaxation function, and $\xi$ ' $(\omega)$ is the Debye peak (Nowick \& Berry, 1972).

In general, linear viscoelastic behavior cannot be described by a single relaxation time. For several independent relaxations $\xi_{\mathrm{j}}$ with characteristic relaxation times $\tau_{\mathrm{j}}$ we can write, by analogy with (1)

$\frac{\mathrm{d} \xi_{\mathrm{j}}}{\mathrm{dt}}=-\frac{1}{\tau_{\mathrm{j}}}\left(\xi_{\mathrm{j}}-\bar{\xi}_{\mathrm{j}}\right)$.

If each relaxation mechanism contributes independently to the total relaxation process of the macroscopic property $\Xi=\sum H_{j} \xi_{j}$, the resulting relaxation process may be characterized by a set of $\tau_{\mathrm{j}}$ or a discrete spectrum $\mathrm{H}_{\mathrm{j}}$ of relaxation times. The real and imaginary parts of the macroscopic property $\Xi$ then can be described by;

$\Xi(\omega)=\Xi_{\infty}+\sum_{j} \frac{H_{j} \xi_{j 0}}{1-i \omega \tau_{j}}$

where $\xi_{\mathrm{j} 0}$ are the relaxed values of $\xi_{\mathrm{j}}, \Xi_{\infty}$ is unrelaxed value of $\Xi$. The relaxation time can alternatively be described by a continuous distribution. This distribution may be fitted by a Gaussian (e.g. Tauke et al., 1968), or a log Gaussian (e.g. Macedo et al., 1968) function. Such a representation introduces, however, a large number of variables, resulting in increased inaccuracies in the calculated relaxation time distribution.

A common empirical representation of stress relaxation is the stretched exponential

$\xi(\mathrm{t})=\exp \left(-\left[\mathrm{t} / \tau_{0}\right]^{\beta}\right)$

where $\beta \leq 1$. Here the case of $\beta=1$ corresponds to single relaxation time behavior as described by Eqns. (1) and (2). The expression (6) is useful for the effective description of the relaxation behavior of materials with a continuous spectrum or a set of discrete relaxation times and is convenient in 
that it involves only two variables, $\tau_{0}$ and $\beta$. The parameter $\beta$ is thus a relative measure for the broadness of relaxation spectrum of the measured property $\xi$ (Brawer, 1985). This representation is also imperfect, often resulting in the calculation of a smaller $\beta$ at short times, and a larger $\beta$ at longer times (Scherer, 1986). All the above representations are empirical to the extent that the relaxation times do not represent specific atomic processes.

Information about the mechanical viscoelastic behavior of highly viscous materials can be obtained by dynamical rheological measurements. For small deformation of a material, the Boltzmann superposition principle applies, and stresses and strains add linearly, with the ratio of the applied stress to the observed strain being a constant independent of the amplitude of the stress (Nowick \& Berry, 1972). For a material subject to small amplitude sinusoidal stress

$\sigma(t)=\sigma_{0} \exp (i \omega t)$,

and the requirement of a linear relationship between stress and strain results in a periodic stress with the same frequency

$\varepsilon(\mathrm{t})=\varepsilon_{0} \exp [\mathrm{i}(\omega \mathrm{t}-\varphi)]$

where $\varphi$ is the loss angle (the phase angle by which the strain lags behind the applied stress). The complex shear modulus $G^{*}(\omega)$ is then

$\sigma(\mathrm{t})=\mathrm{G}^{*}(\omega) \varepsilon(\mathrm{t})$

and the complex shear viscosity $\eta^{*}(\omega)$ is

$\sigma(\mathrm{t})=\eta^{*}(\omega) \dot{\varepsilon}(\mathrm{t})$.

The real component of the shear modulus $G^{\prime}(\omega)$ is a measure of the elastic energy stored per cycle of deformation, the imaginary component of shear modulus $G$ "' $(\omega)$ is a measure of the viscous energy dissipated per cycle.

The form of the general equation between stress and strain is determined by the structural complexity of the tested material. For the case of a material which has only one relaxation process and one relaxation time, the shear modulus of the material can be described by

$\mathrm{G}^{*}(\omega)=\mathrm{G}_{\infty} \frac{\mathrm{i} \omega \tau}{1+\mathrm{i} \omega \tau}$

where $G_{\infty}$ is the shear modulus obtained at $\omega \Rightarrow \infty$ and

$\tau=\eta_{0} / \mathrm{G}_{\infty}$ where $\eta_{0}$ is the relaxed Newtonian viscosity at $\omega \Rightarrow 0$. The real and imaginary parts of the shear modulus are then a pair of Debye functions. It is possible to measure the complex shear modulus $G^{*}(\omega)$ and the complex shear viscosity $\eta^{*}(\omega)$ over a wide range of the dimensionless variable $\omega \tau$ simply by changing both frequency $\omega$, and/or temperature. If the relaxed viscosity of the melt in the temperature range of interest can be described as a function of temperature by an Arrhenian equation, the relaxation time $\tau$ can also be expressed as an Arrhenian equation

$\tau=\tau_{0} \exp (\mathrm{E} / \mathrm{RT})$

where $\mathrm{T}$ is the absolute temperature, $\mathrm{R}$ is the universal gas constant and $\mathrm{E}$ is the activation energy.

In more complicated viscoelastic materials, the deviation from single relaxation time and relaxation process results in a broadening of the shear modulus as a function of frequency with respect to that expected for a Debye function. In silicate melts, for example, besides the main relaxation time associated with $\mathrm{Si}-\mathrm{O}$ bond exchange (Webb \& Dingwell, 1990) there are alkaline peaks, mixed alkali peaks which occur at $\sim 0{ }^{\circ} \mathrm{C}$ for frequency $0.4 \mathrm{~Hz}$ (Day \& Steinkamp, 1969) and a single bonded oxygen peak (Philippoff, 1965). In silicate melts doped with volatiles (for example fluorine) one might expect contributions to the relaxation-time spectrum resulting from the disruption of the three dimensional network of silicate and aluminate tetrahedra and local structural rearrangements.

\section{Experimental procedure}

\section{Sample preparation}

The haplogranite melt (HPG8) is that of Holtz et al. (1992). Its composition is near that of the pseudo ternary minimum at $1 \mathrm{kbar} \mathrm{pH}_{2} \mathrm{O}$ in the system $\mathrm{SiO}_{2}-\mathrm{NaAlSi}_{3} \mathrm{O}_{8}-\mathrm{KAlSi}_{3} \mathrm{O}_{8}-\mathrm{H}_{2} \mathrm{O}$. The starting compositions were chosen to represent $10 \%$ additions of $\mathrm{B}_{2} \mathrm{O}_{3}$ (HPG8B10), $10 \%$ of $\mathrm{P}_{2} \mathrm{O}_{5}$ (HPG8P10), and $10 \%$ of fluorine (HPG8F10) to the haplogranite (HPG8) composition (Table 1).

The melts were stirred for $\sim 24-200 \mathrm{~h}$ using a $\mathrm{Pt}_{80} \mathrm{Rh}_{20}$ viscometry spindle (Webb \& Dingwell, 1990). Cylindrical samples (8 $\mathrm{mm}$ in diameter and $\sim 30 \mathrm{~mm}$ in length) were cored from the crucible using diamond tools and the ends of the cylinders were ground flat. These samples were next placed 

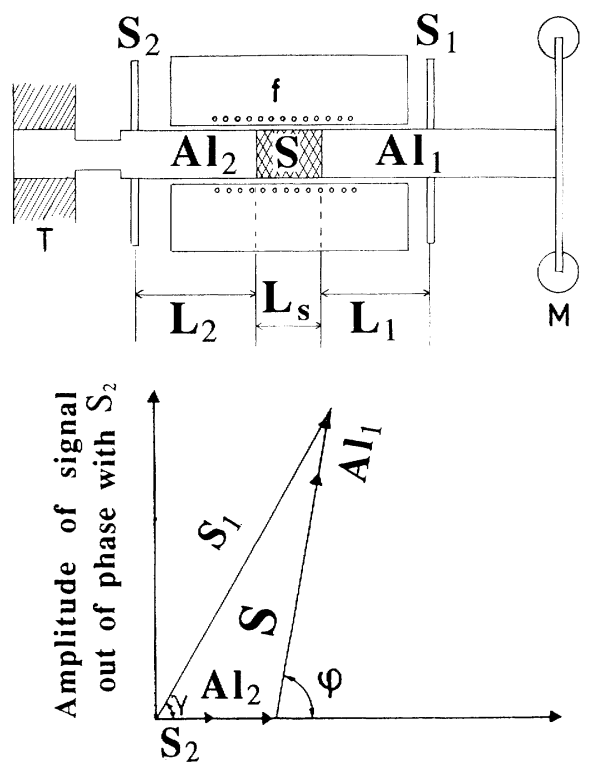

\begin{abstract}
Amplitude of signal in phase with $S_{2}$ ( and the applied stress)
\end{abstract}

Fig. 1. a (top). Scheme of torsion deformation device for the oscillatory shear experiments: $\mathrm{T}$ - fixed end of the alumina $\operatorname{rod} \mathrm{Al}_{2}, \mathrm{~S}$ - sample, $\mathrm{M}$ - moving coil system attached to the alumina rod $\mathrm{Al}_{1}, \mathrm{f}-$ furnace, $\mathrm{S}_{1}$ and $\mathrm{S}_{2}-$ points of angle deformation measurement, $\mathrm{L}_{1}, \mathrm{~L}_{2}, \mathrm{~L}_{\mathrm{s}}-$ length of alumina rods and sample, respectively. - $b$ (bottom). Principal scheme of torsion deformation measurement: $\gamma$ - measured phase shift between channels $S_{1}$ and $S_{2}, \varphi-$ actual phase shift between applied torque and resulting angle of deformation of the sample $S$.

in $\mathrm{Pt}$ foil tubes $(8 \mathrm{~mm}$ in diameter, thickness $0.03 \mathrm{~mm}$, length $50 \mathrm{~mm}$ ) and placed between two alumina rods (A123, Frialit-Degussit ${ }^{\mathbb{}}, 8 \mathrm{~mm}$ in diameter) in a Kanthal ${ }^{\circledR}$ wire-wound horizontal furnace. the free ends of the alumina rods are fixed such that during heating of the assembly, via thermal expansion of the rods, a small axial load is exerted on the rods and the sample, and a good mechanical contact is obtained between them. The assemblage was heated to $\sim 250{ }^{\circ} \mathrm{C}$ above the glass transition temperature, held for $3 \mathrm{~h}$, quenched to the glass transition temperature, and then cooled down slowly over $12 \mathrm{~h}$ to room temperature. This procedure avoids cracking due to thermal stresses during cooling. Finally the platinum jacket was carefully removed from the sample. The two alumina rods with the sample
Table 1. Chemical composition of haplogranite melts (wt \%).

\begin{tabular}{lccll}
\hline Oxide & HPG8 & HPG8B10 & HPG8P10 & HPG8F10 \\
\hline $\mathrm{SiO}_{2}$ & 77.90 & 71.07 & 71.10 & 76.96 \\
$\mathrm{Al}_{2} \mathrm{O}_{3}$ & 11.89 & 11.60 & 11.29 & 11.08 \\
$\mathrm{Na}_{2} \mathrm{O}$ & 4.53 & 4.23 & 3.76 & 4.50 \\
$\mathrm{~K}_{2} \mathrm{O}$ & 4.17 & 3.96 & 3.74 & 4.08 \\
$\mathrm{~B}_{2} \mathrm{O}_{3}$ & - & 8.92 & - & - \\
$\mathrm{P}_{2} \mathrm{O}_{5}$ & - & - & 9.52 & - \\
$\mathrm{F}$ & - & - & - & 4.55 \\
$\Sigma$ & $98.48^{*}$ & $99.78^{* *}$ & $99.36^{*}$ & $98.7^{* * *}$ \\
\hline
\end{tabular}

* Analysis by electron microprobe, Cameca SX-50 in wavelength dispersive mode. Operating conditions $15 \mathrm{kV}, 15 \mathrm{nA}$ on brass, a $10 \mu \mathrm{m}$ defocussed beam and $20 \mathrm{~s}$ count time. Standards were albite $(\mathrm{Na}, \mathrm{Si}, \mathrm{Al})$, orthoclase $(\mathrm{K})$, apatite $(\mathrm{P})$.

** Analysis by ICP-AES methods described in Pichavant et al. (1987) performed at CRPGCNRS Nancy.

*** $\quad \mathrm{F}$ analysis by specific ion electrode performed at CRPG-CNRS Nancy.

melted between them was then installed in the forced oscillation furnace. Microscopic inspection of the samples after the experiments revealed no recrystallization in the sample or on the interfaces between the sample and the alumina rods.

\section{Torsion device}

The forced oscillation torsion apparatus (see Fig. 1 and Kampfmann \& Berckhemer, 1985; Bagdassarov \& Dingwell, 1993), comprises a high temperature horizontal Pt-Rh furnace with an assembly consisting of a cylindrical samples (S) between two alumina torsion-bars $\left(\mathrm{Al}_{1}\right.$ and $\left.\mathrm{Al}_{2}\right)$. The temperature is measured by a type-S thermocouple. Forced harmonic oscillations are applied to the alumina rods and the sample by an electromagnetic moving coil system (M) attached to the free end of the first alumina $\operatorname{rod}\left(\mathrm{Al}_{1}\right)$. The opposite end of the other alumina $\operatorname{rod}\left(\mathrm{Al}_{2}\right)$ is rigidly fixed $(\mathrm{T})$. The pair of aluminum wings $\left(\mathrm{S}_{1}\right.$ and $\mathrm{S}_{2}$ ) is attached perpendicular to the torsion bar. Iron plates at the ends of the wings move in the air gaps of two pairs of capacitive pick-ups. One pair of pick-ups $\left(\mathrm{S}_{2}\right)$ measures angular deformation of the alumina rod with respect to the fixed end $\left(\mathrm{Al}_{2}\right)$. The other pair of pick-ups $\left(\mathrm{S}_{1}\right)$ measures the total angular deformation of the sample plus two rods $\left(\mathrm{Al}_{1}+\mathrm{S}+\mathrm{Al}_{2}\right)$. 
The application of varying frequency sinusoidal oscillations $(0.001-10 \mathrm{~Hz})$ to the moving coil system (M) generates a torque. During each experiment the sinusoidal signals at the two points $\left(\mathrm{S}_{1}\right.$ and $\left.\mathrm{S}_{2}\right)$ were measured. Two periods of each signal were stored in a digital form and later fitted to the theoretical sinusoidal by a least-square method using a conjugate gradient method for the minimization procedure.

For each frequency, the amplitudes $\mathrm{S}_{1}$ and $\mathrm{S}_{2}$ and the phase delay $\gamma$ between the two points of the torsion assemblage have been measured (Fig. 1b). Knowing the distance between the points of measurement and the ends of the sample $\left(\mathrm{L}_{1} \sim 186 \mathrm{~mm}\right.$ and $\mathrm{L}_{2} \sim 190 \mathrm{~mm}$ ), and the applied torque $(\mathrm{T})$, it is possible to calculate the angle of deformation in the alumina rods $\mathrm{Al}_{1}$ and $\mathrm{Al}_{2}$. The angle of deformation $S$ and phase delay $\varphi$ in the sample have been calculated from the simple vector geometry shown in Fig. $1 \mathrm{~b}$. The shear modulus measurements at small angular deformation are based on the linear relationship between applied torque $(\mathrm{T})$ and the resultant torsion angle $(\alpha)$

$\mathrm{G}=\frac{32 \mathrm{~T} 1}{\pi \mathrm{d}^{4} \alpha}$,

where 1 is the length of the specimen and $d$ is the diameter. The torque applied during the dyamic experiment is $\sim 10^{-3} \mathrm{~N} \mathrm{~m}$, and the measured amplitude of the twist deformation between $\mathrm{S}_{1}$ and $\mathrm{S}_{2}$ is $\sim 10^{-5} \mathrm{rad}$.

The applied torque (T) has been calculated from the amplitude of the electrical signal $\mathrm{S}_{2}$ and the calibration of the torsion assemblage before the dynamic measurements. This calibration consists of the stepwise application of static loads (steps of torque $=2 \times 10^{-3} \mathrm{Nm}$ ) at one arm of the coil system (M) and measurement of the amplitude of the $\mathrm{S}_{2}$ signal. The angular deformation at the two points $S_{1}$ and $S_{2}$ is determined from the linear relationship between the electrical signal and the corresponding geometric displacement of the aluminum wings (previously calibrated statically using the same procedure as for the torque calibration). The precision of this method of shear modulus measurement has been checked using a single rod of alumina. The results of these measurements show that (within the error of phase delay measurement $\delta \varphi=10^{-3} \mathrm{rad}$ ) the behavior of the alumina rods is purely elastic and the shear modulus $(\mathrm{G}=161 \pm 3 \mathrm{GPa})$ is independent of frequency $(10-0.001 \mathrm{~Hz})$ and temperature $(22$ to $\left.1000^{\circ} \mathrm{C}\right)$.
The thermal gradient across the sample is less than $3{ }^{\circ} \mathrm{C}$ at all temperatures. The accuracy of shear modulus measurements in the melts is calculated as $\sim 8 \%$, stemming both from uncertainties in length and diameter of the sample at high tenperatures and from uncertainties in the torque and the angular displacement.

\section{Room temperature ultrasonic measurements}

The unrelaxed bulk $\left(\mathrm{K}_{\infty}\right)$ and shear $\left(\mathrm{G}_{\infty}\right)$ moduli of the glasses HPG8, HPG8B10, HPG8P10 and HPG8F10 have been measured at room temperature using the 1- and 2-transducer phase-comparison technique (Jackson et al., 1981) and an ANUTECH $^{\circledR}$ ultrasonic interferometer. Pairs of parallel surfaces were ground and polished at the ends of $\sim 10 \mathrm{~mm}$ long, $8 \mathrm{~mm}$ diameter cylindrical samples of the glasses. Chrome-gold, co-axially plated $20 \mathrm{MHz}$ X-cut (compressional-wave) and AC-cut (shear-wave) quartz transducers were glued to the samples using a 1:1 mixture of glycerin and phthalic anhydride. This method alows the determination of the travel time of elastic waves with high precision. The density of glasses was determined at room temperature by immersion in toluene. The calculated elastic moduli have a total error of less than $0.6 \%$.

\section{Experimental results}

\section{Shear modulus}

The torsion measurements have been carried out in the frequency range $10-0.001 \mathrm{~Hz}$ (with steps of $0.3 \log _{10} \mathrm{~Hz}$ ) and temperature range 500 to $925^{\circ} \mathrm{C}$ (with steps of $25^{\circ} \mathrm{C}$ ). The measurements yield the absolute value of the shear modulus $\left|G^{*}(\omega)\right|^{2}=G^{\prime}(\omega)^{2}+G^{\prime \prime}(\omega)^{2}$ and the phase shift $\varphi(\omega)$ for each temperature. From these data the real G' $(\omega)$, and imaginary G' $(\omega)$, components of the shear modulus have been calculated

$$
\begin{aligned}
& G^{\prime}(\omega)=\left|G^{*}(\omega)\right| \cos [\varphi(\omega)] \\
& G^{\prime \prime}(\omega)=\left|G^{*}(\omega)\right| \sin [\varphi(\omega)] .
\end{aligned}
$$

$G^{\prime}(\omega)$ and $G^{\prime \prime}(\omega)$ at different frequencies and temperatures have been reduced to a master curve via the dimensionless variable $\omega \tau$, where $\tau$ is the relaxation time given by $(12,13)$. The $\mathrm{G}_{\infty}$ is obtained from the torsion experiments at high frequencies and low temperatures. The values of $\mathrm{G}_{\infty}$ measured at high temperatures together with the room-temperature shear and bulk moduli of 
Table 2. Density $\left(20^{\circ} \mathrm{C}\right)$ and elastic moduli of the haplogranite glasses and melts.

\begin{tabular}{|c|c|c|c|c|c|}
\hline \multirow[t]{2}{*}{ sample } & \multirow{2}{*}{$\begin{array}{l}\rho \\
\mathrm{g} \mathrm{cm}^{-3} \\
20^{\circ} \mathrm{C}\end{array}$} & $\begin{array}{l}\mathrm{K} \\
\mathrm{GPa}\end{array}$ & $\begin{array}{l}\mathrm{G} \\
\mathrm{GPa}\end{array}$ & \multirow[t]{2}{*}{$\begin{array}{l}\mathrm{G} \\
\mathrm{GPa}\end{array}$} & $\begin{array}{l}\mathrm{T} * \\
{ }^{\circ} \mathrm{C}\end{array}$ \\
\hline & & \multicolumn{2}{|c|}{ ultrasonic } & & torsion \\
\hline HPG8 & $2.316 \pm 0.005^{1}$ & $36.77 \pm 0.14$ & $29.61 \pm 0.05$ & $26.55 \pm 2.25$ & 650 \\
\hline HPG8P10 & $2.292 \pm 0.005^{3}$ & $32.06 \pm 0.13$ & $27.89 \pm 0.06$ & $26.05 \pm 2.20$ & 670 \\
\hline HPG8B10 & $2.269 \pm 0.005^{1}$ & $34.31 \pm 0.18$ & $24.83 \pm 0.06$ & $21.65 \pm 2.10$ & 566 \\
\hline HPG8F10 & $2.300 \pm 0.005^{2}$ & $32.73 \pm 0.20$ & $23.90 \pm 0.07$ & $22.60 \pm 2.15$ & 491 \\
\hline
\end{tabular}

* Temperature at which the unrelaxed shear modulus $\mathrm{G}_{\infty}$ has been measured in the torsion device.

${ }^{1}$ Knoche, R., Webb, S., Dingwell, D. (1992).

2 Dingwell, D., Knoche, R., Webb, S. (1993a).

${ }^{3}$ Knoche, R. (personal communication).

the glasses are listed in Table 2. The temperature dependence of the shear modulus required to reconcile the high- and low-temperature shear moduli is in the range -3 to $-6 \times 10^{-3} \mathrm{GPa} \mathrm{K}^{-1}$, in agreement with the temperature dependence of the shear moduli of silicate glasses -1 to $-10 \times 10^{-3}$ $\mathrm{GPa} \mathrm{K}^{-1}$ (Bansal \& Doremus, 1986). Table 2 illustrates the decrease in both shear and bulk moduli of these glasses with the addition of boron, phosphorus and fluorine to the HPG8 composition. The addition of these components therefore weakens the structure of the glasses and the melts making them more compressible and less rigid to shear.

The real and imaginary components of the shear moduli measured at different frequencies and temperatures are plotted in Fig. 2. For all four samples the behavior of the complex shear modulus differs significantly from that of a Debye relaxation function. The imaginary component of the shear modulus exhibits an asymmetrical character extending to the high-frequency, lowtemperature range. The amplitude of $\mathrm{G}_{\max }^{\prime \prime} / \mathrm{G}_{\infty}$ is much less than 0.5 as would be the case for a Debye relaxation function. Fig. 2 illustrates the frequency dependent shear modulus of these four melts.

\section{Complex shear viscosity}

The frequency dependent real and imaginary components of shear viscosity $\eta^{*}(\omega)=\eta^{\prime}(\omega)-$ i $\eta^{\prime \prime}(\omega)$ have been calculated from $G^{\prime}(\omega)$ and $G^{\prime \prime}(\omega)$

$\eta^{\prime}(\omega)=G^{\prime \prime}(\omega) / \omega$ and are illustrated in Fig. 3a,b. At a constant temperature, with decreasing frequency the real component of the shear viscosity increases and becomes frequency-independent when it reaches the relaxed Newtonian viscosity $\eta_{0}$ of the melt (Fig. 3a). The frequency-independent values of viscosity are plotted as a function of inverse absolute temperature in Fig. 4 together with the viscosity determined by micropenetration techniques and concentric cylinder techniques (Dingwell et al., 1992, 1993b). An Arrhenian viscositytemperature relationship fits all of the viscosity data for all of the compositions. Even in case of the HPG8B10 melt which represents a mixture of 'strong' (haplogranite) and 'fragile' $\left(\mathrm{B}_{2} \mathrm{O}_{3}\right)$ liquids, an Arrhenian viscosity relationship in the temperature range $650-1650{ }^{\circ} \mathrm{C}$ is apparent. The value of the activation energy of viscous flow decreases with addition of volatiles reflecting the structural changes in haplogranite liquid.

\section{Internal friction}

Viscoelastic behavior of materials is often expressed as the internal friction or the inverse of the mechanical quality factor $\mathrm{Q}^{-1}(\omega)$

$\mathrm{Q}^{-1}(\omega)=\frac{\mathrm{G}^{\prime \prime}(\omega)}{\mathrm{G}^{\prime}(\omega)}=\tan [\varphi(\omega)]$

(O'Connell \& Budiansky, 1978). For single relaxation time behavior $\mathrm{Q}^{-1}(\omega \tau)=(\omega \tau)^{-1}$. The present determination of $\mathrm{Q}^{-1}$ in haplogranite melts as a function of $\omega \tau$ is presented in Fig. 5. For HPG8 melt there is an asymptotic dependence of $\mathrm{Q}^{-1}(\omega \tau \rightarrow \infty) \propto(\omega \tau)^{-0.5}$ and $\mathrm{Q}^{-1}(\omega \tau \rightarrow 0) \propto(\omega \tau)^{-1}$. In the high-frequency, low-temperature range 

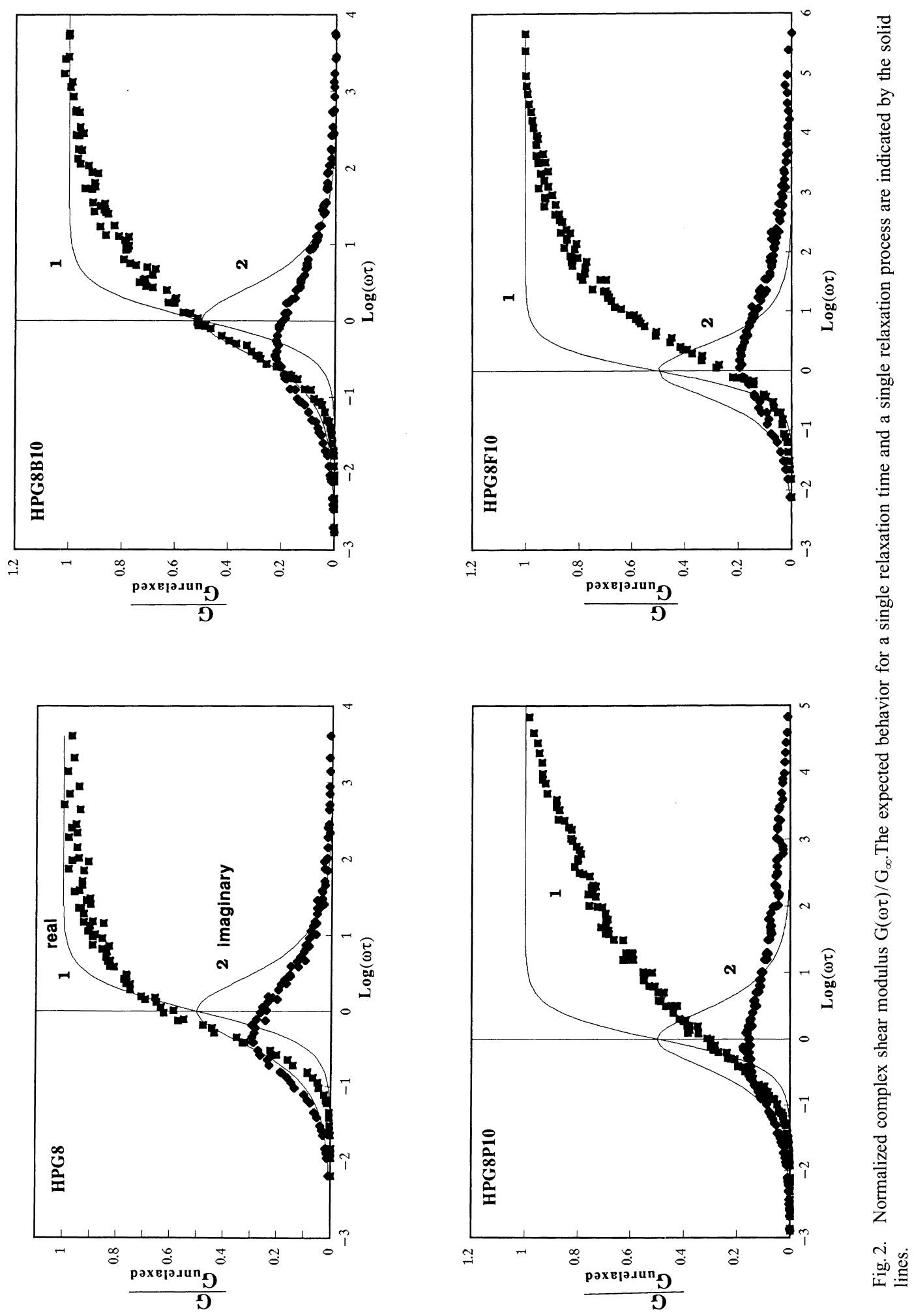


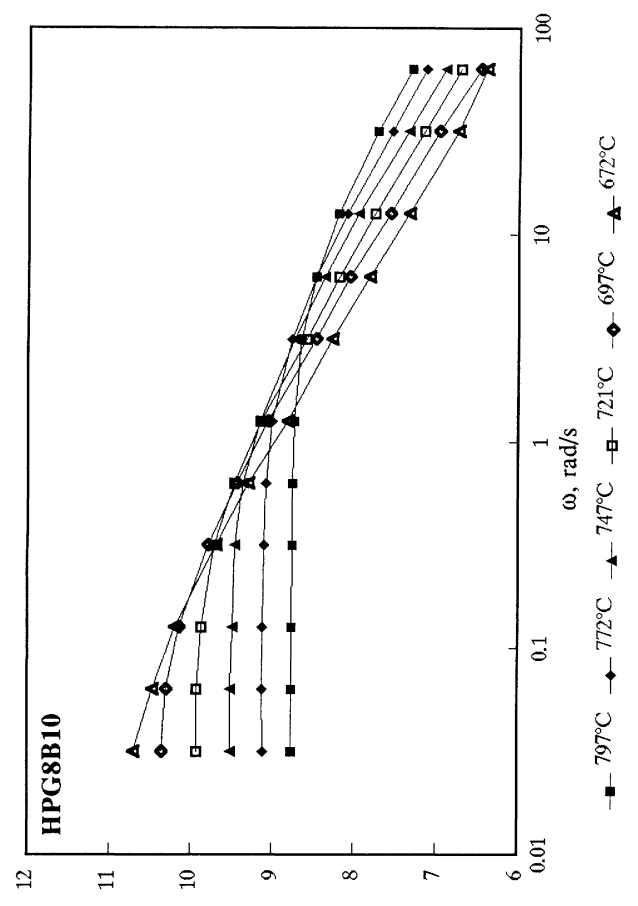

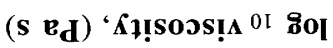

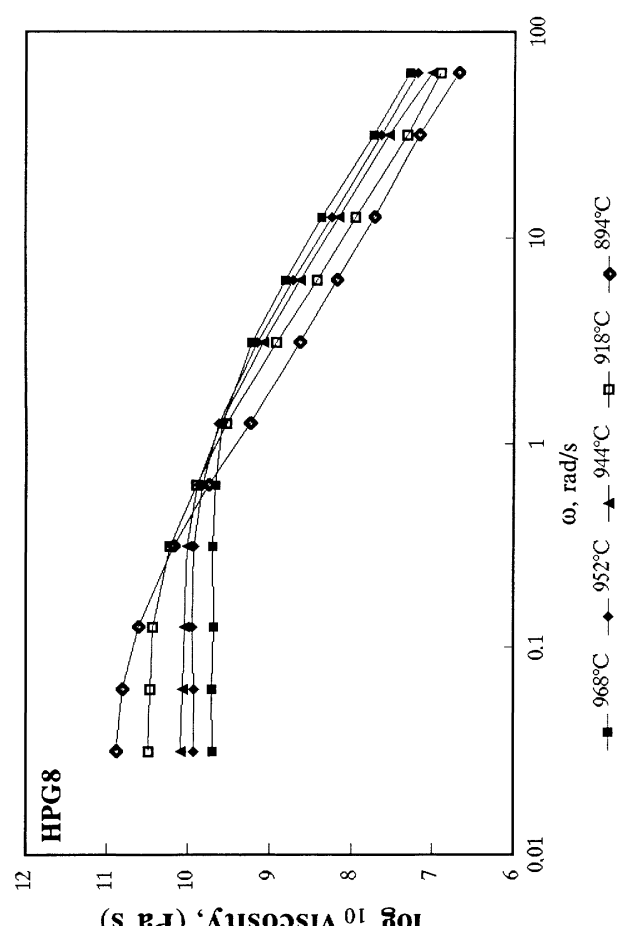

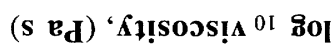
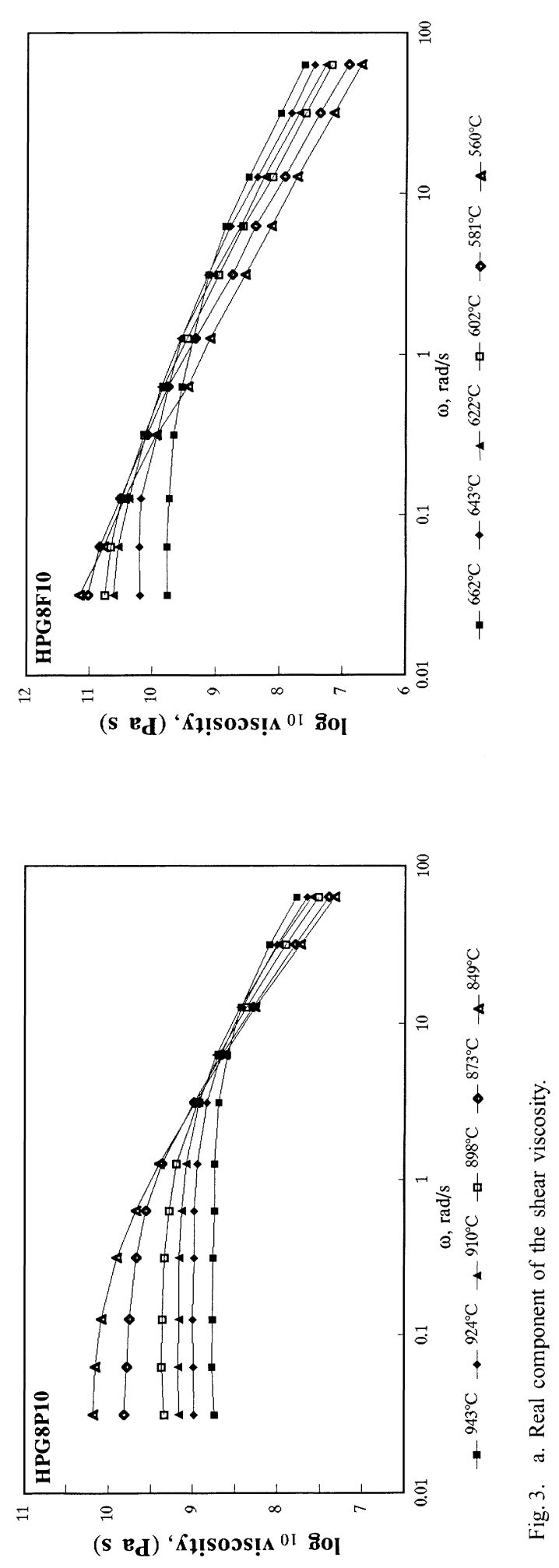


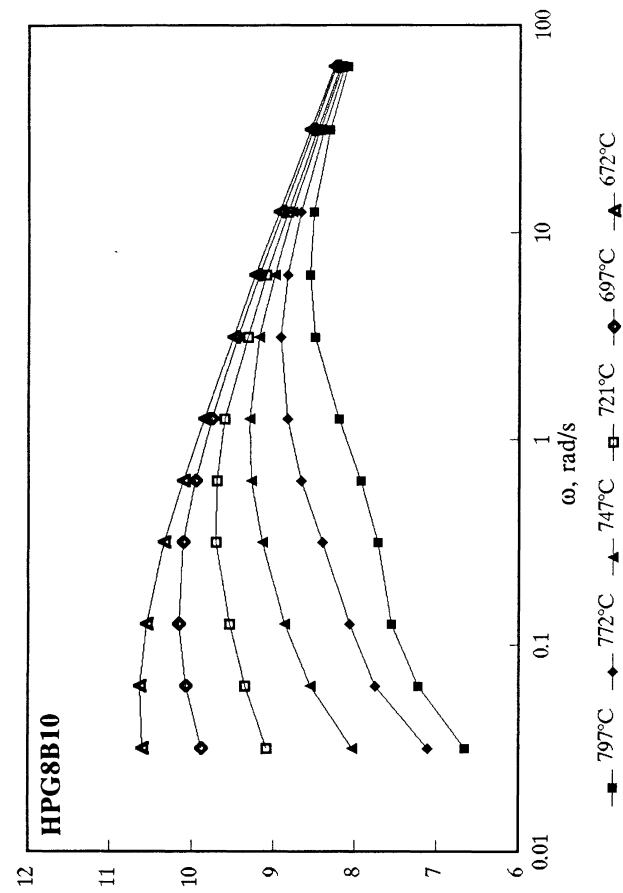

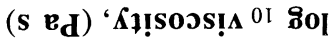

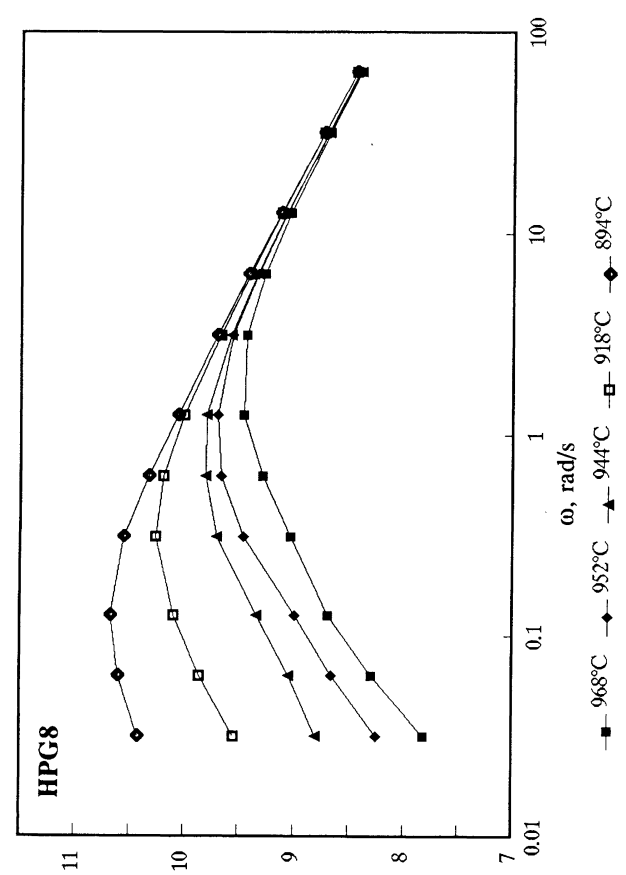

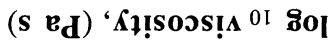
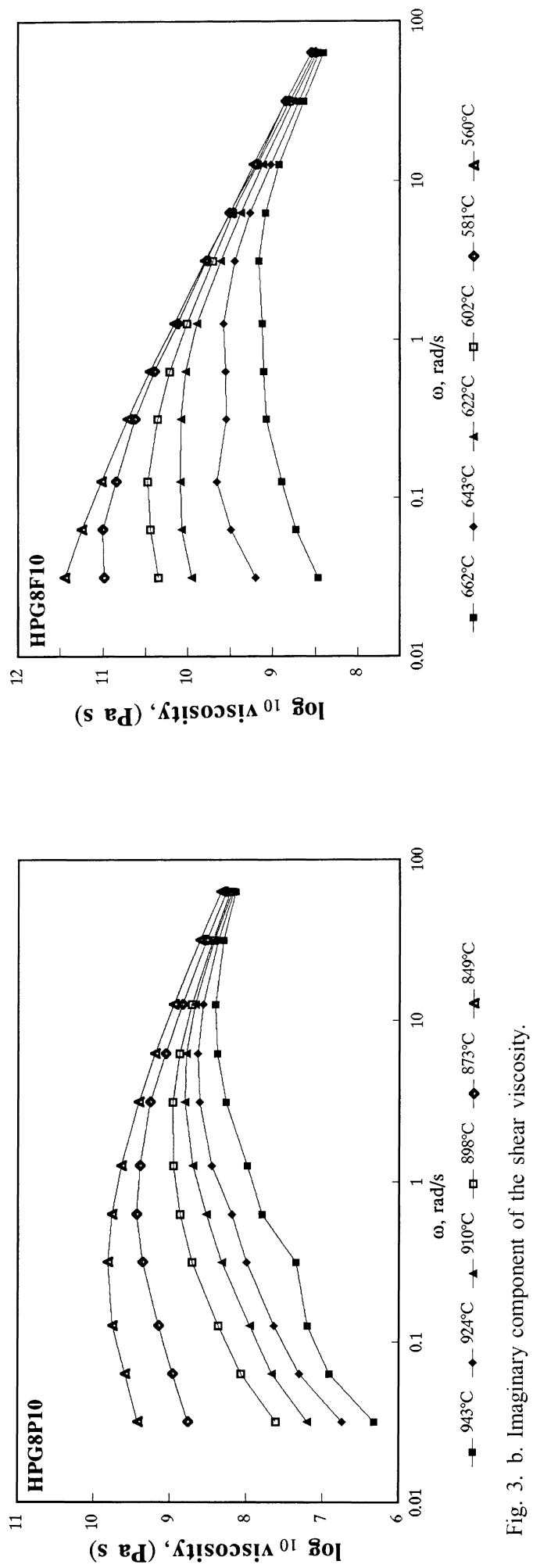

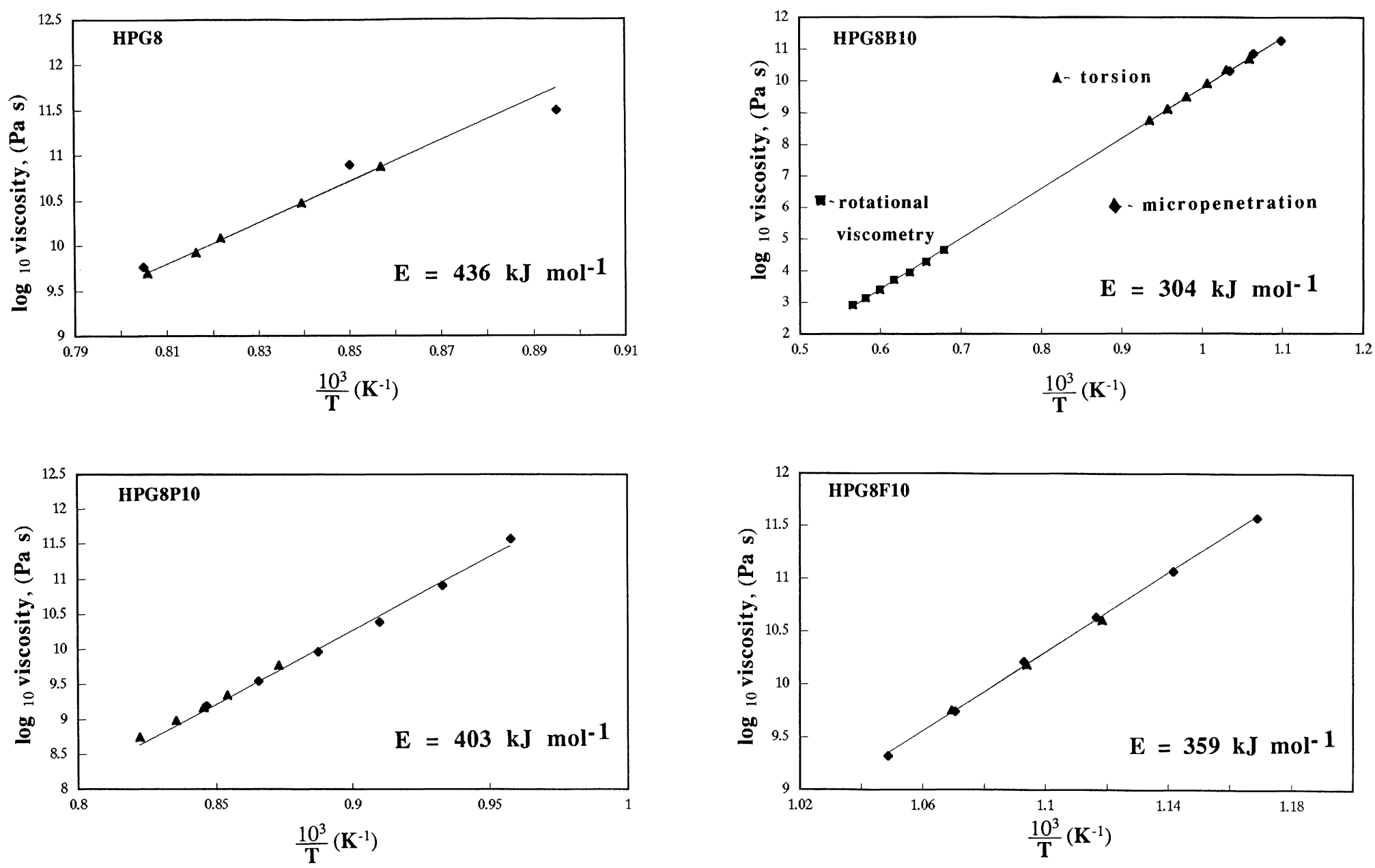

Fig. 4. Relaxed shear viscosity as a function of inverse temperature determined using concentric cylinder, micropenetration and forced oscillation techniques. The activation energy $E$ is calculated using Eqn. (12). 
Stress relaxation in haplogranite melts
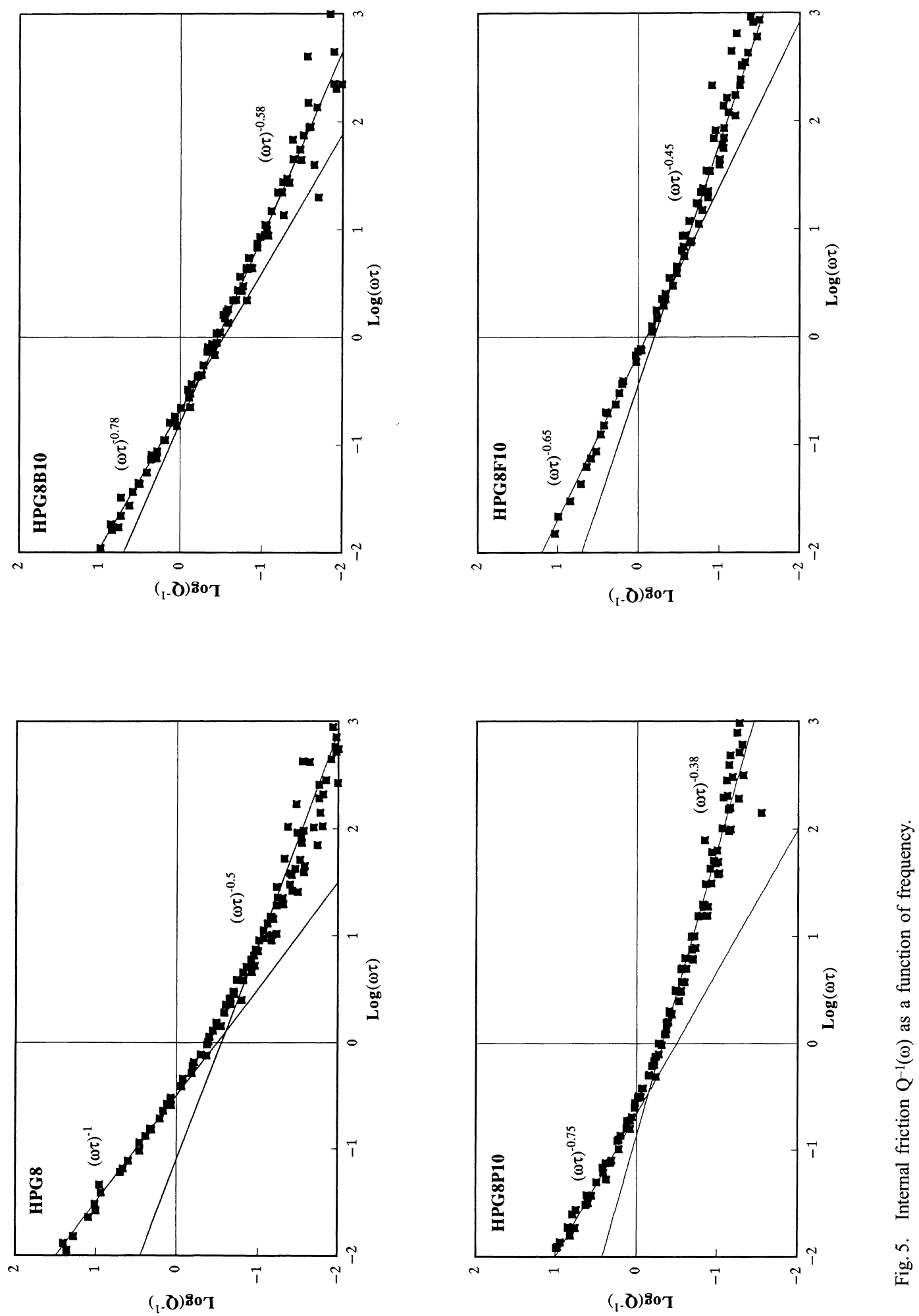

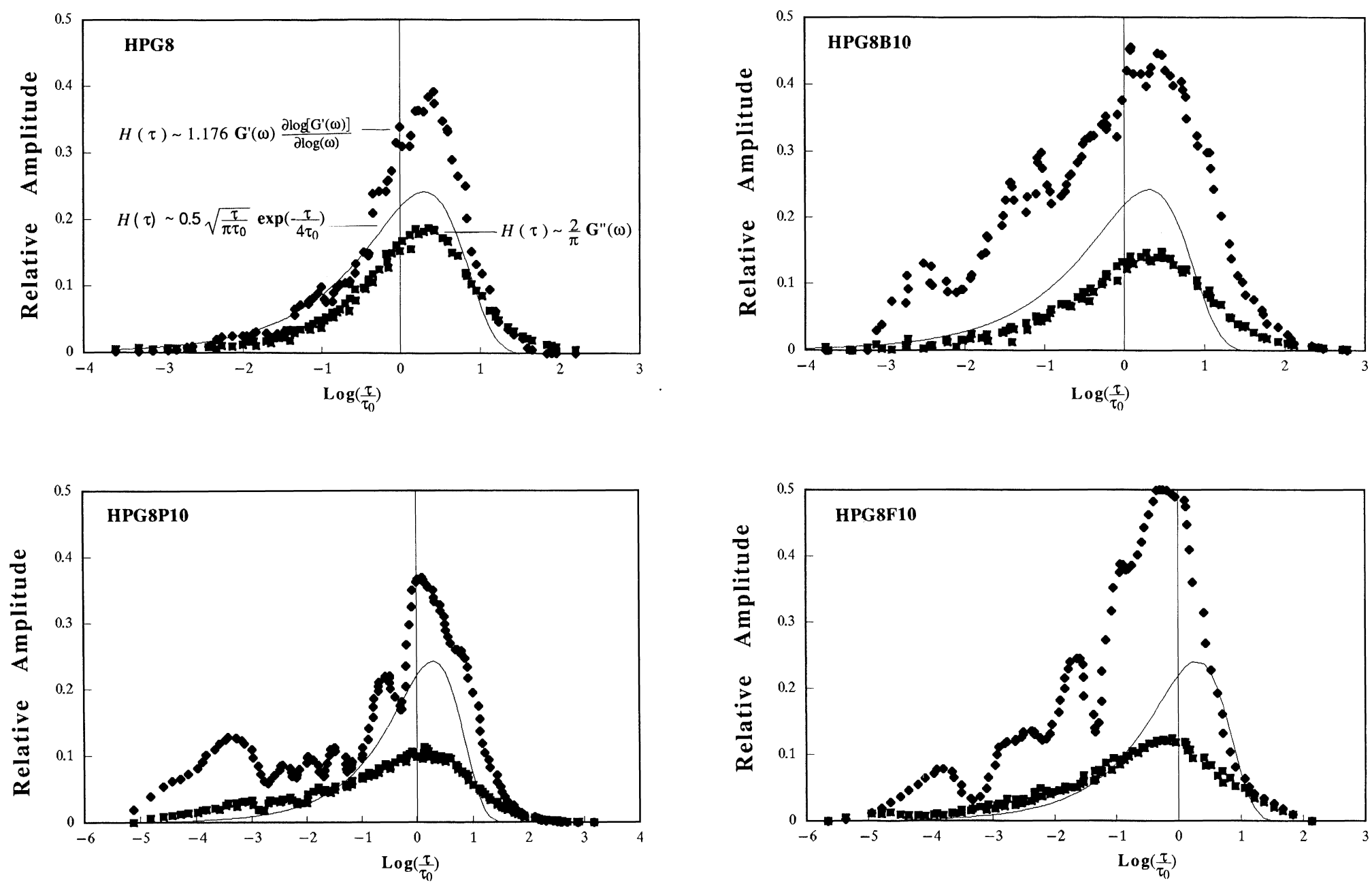

Fig. 6. Shear stress relaxation spectrum: squares - the zero approximation of relaxation spectrum using Eqn. (16), diamonds - the first approximation of relaxation spectrum using Eqn. (17), solid line - theoretical relaxation spectrum for the stretched exponential relaxation with $\beta=0.5$; Eqn. (18). 
$(\omega \tau \rightarrow \infty)$ there is significant deviation from single relaxation time behavior. This deviation from single relaxation time behavior at high viscosities has been observed previously (Kurkjian, 1963; Hopkins \& Jurkjian, 1965; Mills, 1974; Sinning $\&$ Haessner, 1987). The comparison of the asymptotic behavior of $\mathrm{Q}^{-1}$ at high and low $\omega \tau$ shows an increasing deviation from single relaxation time behavior for $\omega \tau \rightarrow 0$ with the addition of boron, phosphorus and fluorine.

\section{Relaxation spectrum}

As the observed frequency-dependent complex shear moduli of these melts cannot be described by a Debye function, it is necessary to fit a distribution of relaxation times to the data. There are a number of possible choices for the form of this distribution. We present here a number of different approaches to this problem.

The complex shear moduli have been used to calculate a relaxation time distribution. The relaxation spectrum $\mathrm{H}\left[\log _{10}(\tau)\right]$ is the contribution to the shear modulus $\mathrm{G}^{*}$ which is associated with the structural relaxation processes having characteristic times lying between $\log _{10} \tau$ and $\log _{10} \tau+$ $\mathrm{d}\left(\log _{10} \tau\right)$ (Nowick \& Berry, 1972). To calculate $\mathrm{H}(\tau)$ from the storage or loss modulus a first approximation can be used (Philippoff, 1965)

$$
\begin{aligned}
& H(\tau) \approx \frac{2}{\pi} G^{\prime \prime}(\omega) \\
& H(\tau) \approx G^{\prime}(\omega) \frac{d \ln \left[G^{\prime}(\omega)\right]}{d \ln (\omega)}
\end{aligned}
$$

The relaxation spectrum approximations $\mathrm{H}(\tau)$ are shown in Fig. 6 . The broad spectrum of relaxation times in the short timescale range is attributed to the different structural environments which exist in silicate melts near the glass transition and which result in different relaxation rates for local structural rearrangements (Jäckle, 1987). The consistent feature of our spectra is the asymmetrical form extended into the range of short relaxation times.

The theoretical stress relaxation spectra for $\beta$-exponent law has an asymmetrical form (Hopkins \& Kurkjian, 1965). For $\beta=0.5$ the analytical expression for the relaxation time spectrum is

$$
\mathrm{H}(\tau) \sim\left[\frac{\tau}{\tau_{0}}\right] 0.5 \exp \left[-\tau /\left(4 \tau_{0}\right)\right] .
$$

The maximum of this function is shifted by $0.3 \log _{10}$ into the faster relaxation range $\left(\tau<\tau_{0}\right)$.
Thus the form and the position of relaxation spectra maximum obtained from experiments on haplogranite samples corresponds to the expression (20) except for the fluorine-bearing melt. The relaxation spectrum of the HPG8 melt is consistent with a $\beta$-relaxation spectrum with $\beta=0.5$.

The shape of the relaxation spectrum can be approximately given by the shape of the loss modulus G" $(\omega \tau)$, but with the $\log _{10}$ time axis increasing from right to left (Mills, 1974). In comparison with the HPG8, the loss moduli of the haplogranite melts doped with boron, phosphorus, and fluorine exhibit longer tails extending to shorter times (see Fig. 6).

Another approach to describe the relaxation time spectrum of these melts is to fit the modulus to a linear combination of single relaxation time elements. In this case

$$
\mathrm{G}^{*}(\omega \tau)=\sum_{\mathrm{i}} \mathrm{H}_{\mathrm{i}} \mathrm{G}_{\mathrm{i}}^{*}\left(\omega, \tau_{\mathrm{i}}\right)
$$

where $\mathrm{G}_{\mathrm{i}}^{*}\left(\omega, \tau_{\mathrm{i}}\right)$ is the modulus of a single relaxation process with a relaxation time $\tau_{\mathrm{i}}$ (see Eqn. (5)). The spectrum of relaxation times $\tau_{i}$ with relative amplitudes $\mathrm{H}_{\mathrm{i}}$ is plotted in Fig. 7. The form of spectrum obtained by this method is also asymmetrical. The relative amplitude of the relaxation time $\tau_{0}$ (Eqn. (12)) decreases with boron, phosphorus or fluorine incorporation into the structure of haplogranite melt. It should be noted that any $\tau_{\mathrm{i}}$ in a spectrum does not correspond to a specific atomic process. Knowledge of the relaxation spectrum $\left(\tau_{\mathrm{i}}, \mathrm{H}_{\mathrm{i}}\right)$ permits calculation of $\mathrm{G}^{\prime}(\omega \tau)$ and $\mathrm{G}^{\prime \prime}(\omega \tau)$ in frequency-temperature space $(\omega \tau)$.

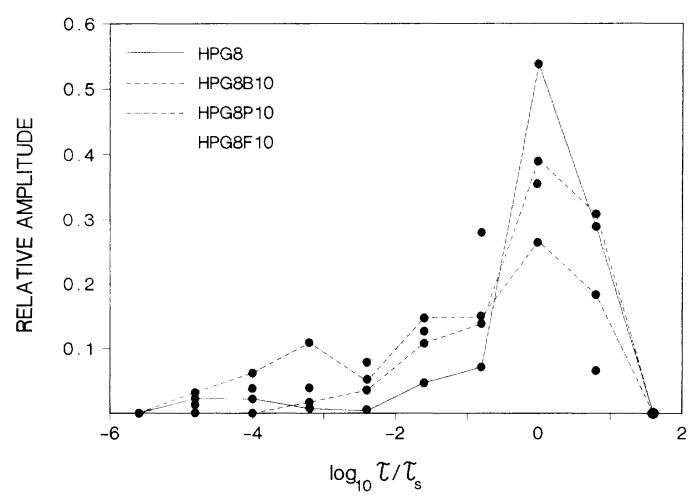

Fig. 7. Calculated discrete stress relaxation spectrum using experimental data on $\mathrm{G}^{*}(\omega \tau)$. 

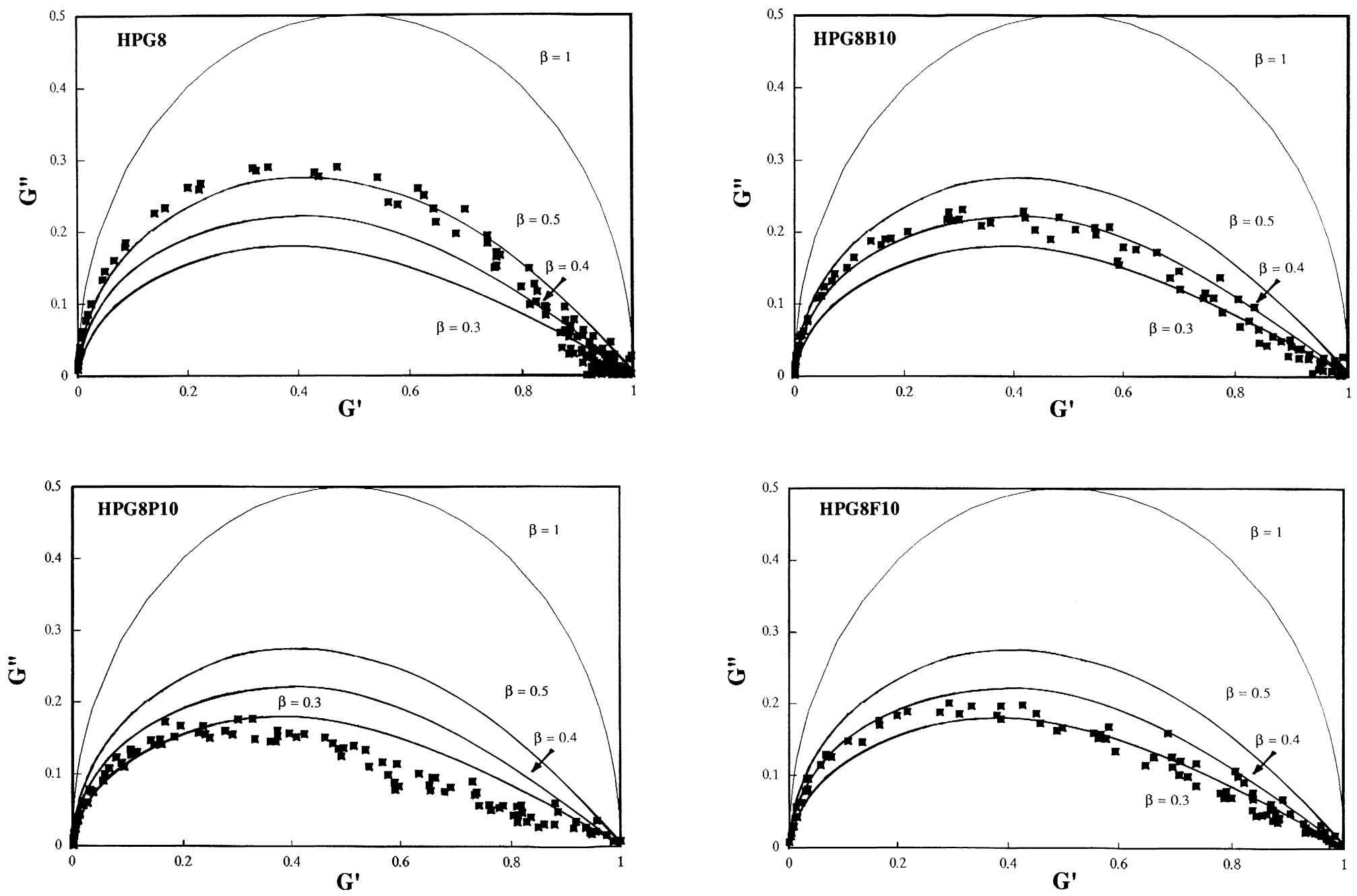

Fig. 8. Cole-Cole diagram. 


\section{Cole-Cole diagram}

Among the methods which are frequently used to display relaxation data is the Cole-Cole diagram (Cole \& Cole, 1941). This is a plot of the imaginary part of the modulus against the real part of the modulus. The conventional Debye relationship results in a semi-circle whose center lies at $G^{\prime}=$ $0.5 \mathrm{G}_{\infty}$ and $\mathrm{G}$ " $=0$ (see Fig. 8). the complex plane representation of the stretched exponential function is a skewed-arc, with G" approaching the axis as a straight line at high frequencies and low temperatures. the effective distribution parameter $\beta$ can be approximated from the angle between the $G$ " $=0$ axis and the high $\omega \tau$ slope of G". This angle is proportional to $\beta \pi / 2$.

The Cole-Cole plots for the haplogranite melts are shown in Fig. 8. The HPG8 sample fits the stretched exponent curve for $\beta=0.5$. The other melt compositions lie near the curve for $\beta \sim 0.3-$ 0.4 .

\section{Discussion}

The effect of the addition of F, P and B on the relaxation spectrum of a granitic melt illustrates the following features. The shift factor for the decrease in temperature associated with viscous relaxation in the F-, B- and P-bearing melts remains well approximated by the Maxwell approximation. The relaxation spectra broaden significantly with the addition of these components. The calculation of a distribution of relaxation times to describe the viscoelastic response of these melts yields a broader distribution for the F-, B- and P-bearing melts than for the haplogranitic base melt. This distribution is most perturbed for the P-bearing melt. The enhanced breadth of the spectra of F-, B- and P-bearing melts necessitates a lower value of the $\beta$ factor in the Kohlrausch stretched exponential description of the relaxation spectra.

The general appearance of the shear moduli of Fig. 4 is most simply interpreted as resulting from an increased number of bonding environments associated with the incorporation of the foreign $(\mathrm{F}, \mathrm{B}, \mathrm{P})$ ions in the melt structure. If complexes of F, P or B with other cations (e.g., aluminophosphate, alkali borate, aluminofluoride) were strongly enough bonded in the granitic melt structure then we might expect the relaxation associated with the lifetime of such species to occur as high-temperature relaxation peaks. Accompanying such a high-temperature peak would be a relaxation mechanism and step change in viscosity at temperatures above the Si-O bond exchange peak. This might particularly be expected for the case of P-bearing granitic melt because the chemical diffusion of $\mathrm{P}_{2} \mathrm{O}_{5}$ in granitic melts has a significantly higher activation energy than that of viscous flow in such systems (Harrison \& Watson, 1984; Chakraborty \& Dingwell, in prep.). In this study we see no evidence for such a higher temperature relaxation involving $\mathrm{P}_{2} \mathrm{O}_{5}$ because the shear viscosities which we calculate above our main relaxation peak are consistent with those measured at much lower strain rates dilatometrically.

In conclusion we wish to stress that not only is the main relaxation peak shifted to lower temperature but the peak is much more skewed towards higher frequency. This high-frequency skewing is consistent with an increase in the variety of bonding sites within the melt. Discrete, detached relaxations due to the added $(\mathrm{B}, \mathrm{F}, \mathrm{P})$ components have not been observed.

Although the results of the present study apply, strictly speaking, to the linear viscoelasticity domain, it has been shown in previous studies that the linear approximation to viscoelasticity provides a useful normalizing factor for scaling the onset on non-Newtonian viscosity in nonlinear, geologically applicable deformation events. The results of this study confirm that although the structure of these melts has been drastically altered by the addition of these components, the width of the viscoelastic domain is only slightly influenced in the low-frequency range. This means that the onset of non-Newtonian viscosity in this variety of melt structures can be approximated with the Maxwell relation.

\section{Conclusions}

1. The strain rate - temperature dependence of shear viscosity and modulus of the studied haplogranite melts differs from that of single relaxation time viscoelatic behavior.

2. The viscoelastic behavior of haplogranite melt follows stretched exponent relaxation with parameter $\beta=0.5$ with an Arrhenian temperature dependence of the shear viscosity indicating 'strong' liquid behavior.

3. The addition of $\mathrm{B}_{2} \mathrm{O}_{3}, \mathrm{P}_{2} \mathrm{O}_{5}$, or $\mathrm{F}_{2} \mathrm{O}_{-1}$ into the haplogranite melt results in increased stretched exponential relaxation with parameter $\beta<0.5$ and in broadening of the stress relaxation 
spectrum over 6-7 decades of $\log _{10}$ time units in comparison to the $\sim 5 \log _{10}$ time units width observed for HPG melt.

4. The addition of $\mathrm{B}_{2} \mathrm{O}_{3}, \mathrm{P}_{2} \mathrm{O}_{5}$, or $\mathrm{F}_{2} \mathrm{O}_{-1}$ results in a decrease of the room-temperature bulk and shear modulus and high-temperature shear modulus with respect to that of HPG. The addition of these components weakens the structure of the melts making their structure more compressible and less rigid.

Acknowledgements: This work was supported by the Alexander von Humboldt Foundation. The authors thank Prof. H. Berckhemer for lending torsion device, Prof. M. Rosenhauer for discussions, K. Klasinski for developing the electronics and software of the torsion device, R. Knoche for micropenetration and density measurements, D. Krauße for microprobe analysis, G. Gollner, A.-M. Dietel for chemical analysis, H. Schulze for sample preparation and G. Herrmannsdörfer for technical help.

\section{References}

Bagdassarov, N. S. \& Dingwell, D. B. (1993): Frequency dependent rheology of vesicular rhyolite. J. Geophys. Res. (in press).

Bansal, N. P. \& Doremus, R. H. (1986): Handbook of glass properties. Academic Press, San-Diego, Calif., 300 pp.

Brawer, S. (1985): Relaxation in viscous liquids and glasses. The American Ceramic Society, Columbus, Ohio, 220 pp.

Cole, K. S. \& Cole, R. H. (1941): Dispersion and absorption in dielectrics. J. Chem. Phys., 9, 341-351.

Day, D. E. \& Steinkamp, W. E. (1969): Mechanical damping spectrum for mixed-alkali $\mathrm{R}_{2} \mathrm{O} \cdot \mathrm{Al}_{2} \mathrm{O}_{3} \cdot 6 \mathrm{SiO}_{2}$ glasses. J. Amer. Ceram. Soc., 52, 571-574.

Dingwell, D. B., Knoche, R., Webb, S. L. (1993a): The effect of fluorine on the density of haplogranite melt. Am. Mineral. In press.

$---(1993 b)$ : The effect of $\mathrm{P}_{2} \mathrm{O}_{5}$ on the viscosity of haplogranitic liquids. Eur. J. Mineral., 5, 133-140.

Dingwell, D. B., Knoche, R., Webb, S. L., Pichavant, M. (1992): The effect of $\mathrm{B}_{2} \mathrm{O}_{3}$ on the viscosity of haplogranitic liquids. Am. Mineral., 77, 457-461.

Dingwell, D. B. \& Webb, S. L. (1989): Structural relaxation in silicate melts and non-Newtonian melt rheology in geological processes. Phys. Chem. Mineral, 16, 508-516.

- (1990): Relaxation in silicate melts. Eur. J. Mineral., 2, 427-449.

Farnan, I. \& Stebbins, J. F. (1990a): A high temperature ${ }^{29} \mathrm{Si}$ NMR investigation of solid and molten silicates. J. Am. Chem. Soc., 112, 32-39.
- - (1990 b): Observation of slow atomic motions close to the glass transition using 2-D ${ }^{29} \mathrm{Si}$ NMR. J. NonCryst. Sol., 124, 207-215.

Harrison, T. M. \& Watson, E. B. (1984): The behavior of apatite during crustal anatexis: Equilibrium and kinetic consideration. Geochim. Cosmochim. Acta, 88, 1467-1477.

Holtz, E., Behrens, H., Dingwell, D. B., Taylor, R. P. (1992): Water solubility in aluminosilicate melts of haplogranitic compositions at 2 kbars. Chem. Geol., 96, 289-302.

Hopkins, I. L. \& Kurkjian, C. R. (1965): Relaxation Spectra and Relaxation Processes in Solid Polymers and Glasses. In Mason, W. P. (ed.), Physical Acoustics. Principles and Methods. 2, Part B, 91-164.

Jackson, I., Niesler, H., Weidner, D. (1981): Explicit correction of ultrasonically determined elastic wave velocities for transducer-bond phase shifts. J. Geophys. Res., 86, 3736-3748.

Jäckle, J. (1987): Theory of glass transitions. New thoughts about old facts. Phil. Mag. B, 56,113-127.

Kampfmann, W. \& Berckhemer, H. (1985): High temperature experiments on the elastic and anelastic behavior of rocks. Phys. Earth Planet. Int., 40, 223 -237 .

Knoche, R., Webb, S. L., Dingwell, D. B. (1992): A partial molar volume for $\mathrm{B}_{2} \mathrm{O}_{3}$ in haplogranitic melt. Canad. Mineral., Spec. Issue on Pegmatites, 30, 561-569.

Kurkjian, C. R. (1963): Relaxation of torsional stress in the transformation range of a soda-lime-silica glass. Phys. Chem. Glass., 4, 128-136.

Liu, S. B., Stebbins, J. F., Schneider, E., Pines, A. (1988): Diffusive motion in alkali silicate melts: an NMR study at high temperature. Geochim. Cosmochim. Acta, 52, 527-538.

Macedo, P. B., Simmons, J. H., Haller, W. (1968): Spectrum relaxation times and fluctuation theory: ultrasonic studies on an alkali-borosilicate melt. Phys. Chem. Glass., 9, 156-164.

McMillan, P. F., Wolf, G. H., Poe, B. T. (1992): Vibrational spectroscopy of silicate melts and glasses. Chem. Geol., 96, 351-366.

Mills, J. J. (1974): Low frequency storage and loss moduli of soda-silica glasses in the transformation range. J. Non-Cryst. Sol., 14, 255-268.

Nowick, A. S. \& Berry, B. S. (1972): Anelastic Relaxation in Crystalline Solids. Academic Press, New York - London, 677 pp.

O'Connell, R. J. \& Budiansky, B. (1978): Measures of dissipation in viscoelastic media. Geophys. Res. Lett., 5, 5-8.

Pichavant, M., Valencia Herrera, J., Boulmier, S., Briqueu, L., Joron, J.-L., Juteau, M., Marin, L., Michard, A., Sheppard, S. M. F., Treil, M., Vernet, M. (1987): The Macusani glasses, SE Peru: evidence of chemical fractionation in peraluminous magmas. Geochem. Soc. Spec. Pub., 1, 359-373.

Philippoff, W. (1965): Relaxation in Polymer Solutions, Liquids, and Gels. In Mason, W. P. (ed.), Physical 
Acoustics. Principles and Methods. 2, Part B, $1-90$.

Rivers, M. L. \& Carmichael, I. S. E.: Ultrasonic studies of silicate melts. J. Geophys. Res., 92, 92479270.

Sato, H. \& Manghnani, M. H. (1985): Ultrasonic measurements of $\mathrm{V}_{\mathrm{p}}$ and $\mathrm{Q}_{\mathrm{p}}$ : Relaxation spectrum of complex modulus on basalt melts. Phys. Earth Planet. Inter, 42, 18-33.

Scherer, G. W. (1986): Relaxation in glass and composites. Wiley-Interscience Publication, New York, $331 \mathrm{pp}$.

Silver, L. A. (1988): Water in silicate glasses. Ph. D. Thesis, Cal. Tech., 238 pp.

Sinning, H.-R. \& Haessner, F. (1987): Determination of the glass transition temperature of metallic glasses by low-frequency internal friction measurements. J. Non-Cryst. Sol., 93, 53-66.

Stebbins, J. F., Farnan, I., Yue, X. (1992): The structure and dynamics of alkali silicate liquids: A view from NMRspectroscopy. Chem. Geol., 96, 371-386.

Tauke, J., Litovitz, T. A., Macedo, P. B (1968): Viscous relaxation and non-Arrhenius behavior in $\mathrm{B}_{2} \mathrm{O}_{3}$. J. Amer. Ceram. Soc., 51, 158-163.

Webb, S. L. \& Dingwell, D. B. (1990): Non-Newtonian rheology of igneous melts at high stresses and strain-rates: experimental results for rhyolite, andesite, basalt and nephelinite. J. Geophys. Res., 94, 15695-15701.

Received 17 August 1992

Accepted 2 February 1993 
